\author{
シリコンアバランシェフォトダイオード \\ フォトンカウンティングモジュールを用いた \\ $1 \mu \mathrm{m}$ 帯ライダー信号の特性 \\ 辰巳 賢二, 今井 正 \\ 宇宙開発事業団 技術研究本部（３ 305-0047 茨城県つくば市千現 2-1-1）

\section{Characteristics of Lidar Signal Using Silicon Avalanche Photodiode Single Photon-Counting Module}

\author{
Kenji TATSUMI and Tadashi IMAI \\ Office of Research and Development, National Space Development Agency of Japan \\ 2-1-I Sengen, Tsukuba, Ibaraki 305-0047
}

(Received July 30, 1998)

\begin{abstract}
This paper reports the characteristics of $1 \mu \mathrm{m}$ lidar signal using Silicon Avalanche Photodiode (Si-APD) single photon-counting module. The transmitter of the lidar is a laser diode pumped Q-switched Nd:YAG laser with the wavelength of $1064 \mathrm{~nm}$. The beam divergence is $0.5 \mathrm{mrad}$. The diameter of the receiver telescope is 300 $\mathrm{mm}$ and the field of view is $0.7 \mathrm{mrad}$. The receiver employs a photon-counting-solid state Geiger mode Si-APD module whose model number is SPCM-AQ-212 which was made by EG\&G, Canada. The atmospheric observations were performed using the lidar at Tsukuba Space Center in November 7, 1997. It was very clear day and there was not a speck of cloud in the sky. Experimental results show that the distribution of received photo-electron signal from the atmosphere is a near Poisson's distribution, and signal-to-noise ratio increases proportional to the square root of accumulation.
\end{abstract}

Key Words: Lidar, Single photon-counting, Si-avalanche photodiode, Laser diode pumped Q-switched Nd:YAG laser

\section{1.まえがき}

地球温暖化に代表される気候変動の将来予測を精度良 く行う上で, 海洋の影響とともに最も不確実な雲の振る舞 いを明らかにすることが求められている，特に,雲の3次元 分布構造, 及び上層の薄い雲の分布については, 放射収支 との関倸からその実体の解明が求められている。ライ ダーを衛星に搭載することにより,巻雲・エアロゾル・水 蒸気量及び風などの地球環境をグローバルに観測するこ とが可能になる。この目的のため, 日本では宇宙開発事業 団がライダー実証衛星計画1)を進めており, 米国ではNASA がGLAS (Geoscience Laser Altimeter System) 2) でエアロゾ ル,雲の観測を行う計画を立てている。これらのライダー では, 光信号検出にシリコンアバランシェフォトダイオー ド(Si-APD)が用いられることになっている.

一方, ライダー信号の検出法として, 単一光子計数検出 法(Single Photon-Counting Method)が広く用いられている が, 光電変換素子としては光電子増倍管が今までは主流で あった。最近, 量子効率の高いSi-APDを用いたフォトンカ ウンティングモジュール3,4)が用いられるようになってき
た.しかし感度が最大となる波長 $0.5 \mu \mathrm{m}$ 帯5) での使用が一

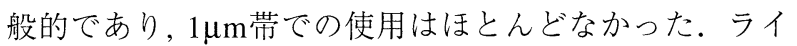
ダー実証衛星では, $1 \mu \mathrm{m}$ 帯の光信号検出にSi-APDを用いた フォトンカウンティングを用いることが計画1)されてお り,受信信号の基本特性の把握が必要である.

本論文では, $1 \mu \mathrm{m}$ 帯のライダーにSi-APDフォトンカウン テイングモジュールを用いて大気観測を行い, 得られたラ イダー信号の特性について解析を行った結果について報 告している.

\section{2. 信号対雑音比 $(S / N)$ の計算}

ライダー方程式は良く知られているように, 次式で書け る).

$$
\begin{aligned}
& n_{\mathrm{s}}(z)=\frac{E_{0} \cdot T_{\mathrm{T}} \cdot T_{\mathrm{R}} \cdot Y \cdot A_{\mathrm{R}} \cdot \Delta z \cdot T^{2}(z) \cdot \beta(z)}{z^{2}} \cdot \frac{\eta \cdot \lambda}{h \cdot c} \\
& T(z)=\exp \left\{-\int_{0}^{z} \alpha\left(z^{\prime}\right) \mathrm{d} z^{\prime}\right\}
\end{aligned}
$$


ここで, $N_{\mathrm{s}}(z)$ : ゲート時間内の受信光電子数, $\eta$ : 量子効 率, $A_{\mathrm{R}}$ : 受信開口面積, $c:$ 光速度, $T(z):$ 大気透過率, $z$ : 観 測対象の高度, $\beta(z)$ : 体積後方散乱係数, $\alpha(z)$ : 消散係数, $E_{0}$ ：レーザー出力エネルギー, $h$ : プランク定数, $\lambda:$ レー ザー発振波長, $\Delta z$ : 垂直分解能, $Y$ : 受信視野内に占める送 信エネルギー割合, $T_{\mathrm{T}}$ : 送信光学系効率, $T_{\mathrm{R}}$ : 受信光学系 効率である。

ライダーにおける受信光データは, 1 計測において各ゲー 卜時間に対応したM個の時系列データとして取得され，同 条件の計測を $\mathrm{N}$ 回繰り返すことにより要素数 $\mathrm{M} \times \mathrm{N}$ 個の データセットが得られる。Fig.1に取得データヒットの関 係を示す．横軸は測定回数で, 縦軸は高度に相当した時間 である。i回目の測定における,時間 (高度)jにおける測定值 を $n_{\mathrm{ij}}$ とする．測定值 $n_{\mathrm{ij}}$ は加算回数に依存している.

各ゲート時間(高度に対応)に対する $S / N$ は定義より，一連 の同条件計測データセット(時間 $j$ 固定)より求められる 信号の平均值 $\bar{n}_{j}^{\text {s }}$, 計測の標準偏差 $\sigma_{j}$ を用いて次式で計算さ れる。

$$
\begin{aligned}
(S / N)_{j} & \equiv \bar{n}_{j}^{\mathrm{s}} / \sigma_{j} \\
\bar{n}_{j}^{\mathrm{s}} & =\frac{1}{\mathrm{~N}} \sum_{\mathrm{i}=1}^{\mathrm{N}} n_{\mathrm{ij}}^{\mathrm{s}}, \quad \bar{n}_{j}=\frac{1}{\mathrm{~N}} \sum_{\mathrm{i}=1}^{\mathrm{N}} n_{\mathrm{i} j} \\
\sigma_{j}^{2} & =\frac{1}{\mathrm{~N}} \sum_{\mathrm{i}=1}^{\mathrm{N}}\left(n_{\mathrm{i} j}-\bar{n}_{j}\right)^{2}=\bar{n}_{j}^{2}-\bar{n}_{j}^{2}
\end{aligned}
$$

ここで,APDを用いたフォトンカウンティング計測を考え る。あるゲート時間に対する入射光の確率分布は, 良く知 られているようにPoisson分布する7). 平均值を $m$, 変数を $x=0,1,2, \ldots$ とすると, 確率密度関数は次式で表せる.

$$
P(x)=\frac{m^{x} e^{-m}}{x !}
$$

また，分散 $\sigma_{x}^{2}$ と標準偏差 $\sigma_{x}$ は, それぞれ

$$
\sigma_{x}^{2}=m, \quad \sigma_{x}=\sqrt{m}
$$

となる。すなわち平均值と分散值は等しい.

ライダー計測の場合, 入射光 $n_{i j}$ は観測対象である雲, エア ロゾル, 空気分子からの信号光 $n_{\mathrm{ij}}^{\mathrm{s}}$, 地表・雲等による背景 光 $n_{\mathrm{i} j}^{\mathrm{b}}$ 及びダークカウント $n_{\mathrm{ij}}^{\mathrm{d}}$ で構成され, それらの線形結合 で表される。すなわち，

$$
n_{\mathrm{ij}}=n_{\mathrm{ij}}^{\mathrm{s}}+n_{\mathrm{ij}}^{\mathrm{b}}+n_{\mathrm{ij}}^{\mathrm{d}}
$$

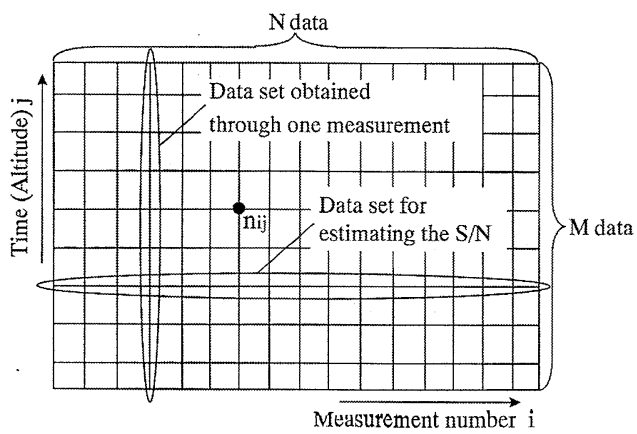

Fig.1 Data set obtained through measurements.
である。したがって分散值 $\sigma_{j}^{2}$ は $\sigma_{j}^{2}=\bar{n}_{j}$ であり, 結局 $S / N$ は 次式となる。

$$
S / N=\bar{n}_{j}^{\mathrm{s}} / \sqrt{\bar{n}_{j}}
$$

一方，この式の分子 $\bar{n}_{j}^{\mathrm{s}}$ は, $\bar{n}_{j}=\bar{n}_{j}^{\mathrm{s}}+\bar{n}_{j}^{\mathrm{B}}, \bar{n}_{j}^{\mathrm{B}}=\bar{n}_{j}^{\mathrm{b}}+\bar{n}_{j}^{\mathrm{d}}$ であ るので, $\bar{n}_{j}^{\mathrm{s}}=\bar{n}_{j}-\bar{n}_{j}^{\mathrm{B}}$ で計算出来る. 背景光雑音とダークカ ウントは時間に依らず, その平均值が一定とすると, 計測 データセットより $n_{\mathrm{i} j}^{\mathrm{s}}<<n_{\mathrm{i} j}^{\mathrm{B}}$ となる時間ゲートでのデータを 取り出してデータセットを作り, その平均值を求めればよ い.したがって,S/Nは,

$$
S / N=\left(\bar{n}_{j}-\bar{n}^{\mathrm{B}}\right) / \sqrt{\bar{n}_{j}}
$$

となる。

加算回数を $\mathrm{K}$ とすると, 各測定における取得デー夕は独 立であり, 平均值, 分散はそれぞれK倍されるので,

$$
S / N=\sqrt{\mathrm{K}} \cdot\left(\bar{n}_{j}-\bar{n}^{\mathrm{B}}\right) / \sqrt{\bar{n}_{j}}
$$

となる。

\section{3. 実験装置構成}

実験に用いたライダーの構成をFig.2に示す。また, 実験 装置の仕様值をTable 1に示す。レーザー発振器は, LD励起 Qスイッチ Nd:YAGレーザーである，発振波長は1064nm, 出力は最大 $100 \mathrm{~mJ}$, パルス幅は $30 \mathrm{~ns}$, パルス繰り返しは $30 \mathrm{pps}$ である．送信望遠鏡を出たところでの送信光の出力は実 測值で $28 \mathrm{~mJ}$, ビーム拡がり角は $0.5 \mathrm{mrad} ゙$ ある.

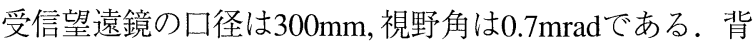
景光雑音を除去するため, 帯域幅2nmの干渉フィル夕を光 路中に挿入している. 光検出器のリニアリティを確保す るため, NDフィルタにより光検出器への入射光レベルを調 整した。NDフィルタの透過率は, $\pm 5 \%$ 以下で校正されて いる。また, 受信光学系の透過率は, 各構成素子の透過率 または反射率を積分球などを用いて分光測定し，その積よ り算出している．各構成素子の測定精度は土10\%以下であ る。なお, 送受光軸の間隔は $880 \mathrm{~mm}$ である。このように, 送 受光軸間にパララックスがあるので, 受信視野内に送信 ビーム光がすべて入る高度は $2.5 \mathrm{~km}$ 以上である。高度 $2.5 \mathrm{~km}$ 以下の受信信号には, 受信視野と送信ビーム広がりと のオーバーラップ関数Yを考慮しなければならない.

光検出器にはEG\&G社製のSi-APDフォトンカウンティ

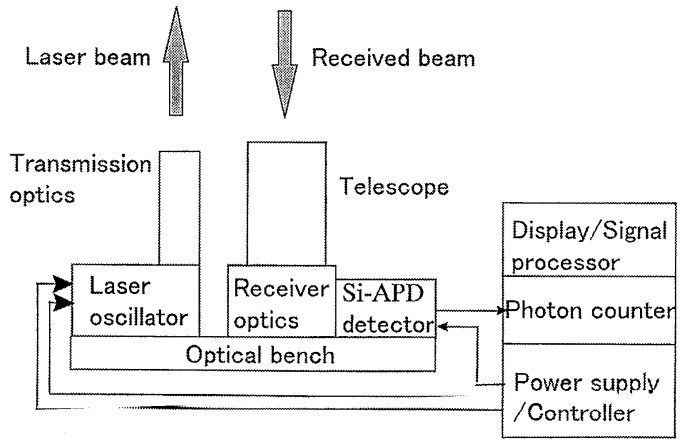

Fig.2 The schematic of the lidar. 
Table 1 The specifications of the lidar

\begin{tabular}{lll}
\hline \hline & Items & \multicolumn{1}{c}{ Specifications } \\
\hline $\begin{array}{ll}\text { Transmit- } \\
\text { ter }\end{array}$ & Laser & LD pumped Q-switched \\
& Wavelength & $1064 \mathrm{~nm}$ \\
& Laser output energy & $100 \mathrm{~mJ}$ (Maximum) \\
& Transmitted energy & $28 \mathrm{mI}$ \\
& Pulse repetition rate & $30 \mathrm{pps}$ \\
& Pulse width & $30 \mathrm{~ns}$ \\
& Beam divergence & $0.5 \mathrm{mrad}$ \\
\hline \multirow{4}{*}{ Receiver } & Diameter of telescope & $300 \mathrm{~mm}{ }^{\phi}$ \\
& Transmission & Variable using Nd filter \\
& Field of view & $0.7 \mathrm{mrad}$ \\
& Band width of filter $2 \mathrm{~nm}$ \\
& Parallax & $880 \mathrm{~mm}$ \\
\hline \multirow{3}{*}{ Detector } & Ditection method & Si-APD Single Photon-Counting \\
& Model number & EG \& G: SPCM-AQ-212 \\
& Detection probability & $1.0 \% @ 1064 \mathrm{~nm}$ \\
& Dark counts & $500 \mathrm{c} / \mathrm{s}$ \\
\hline & Vertical resolution & $75 \mathrm{~m}(\mathrm{Gate}$ time 500 ns) \\
\hline \hline
\end{tabular}

ングモジュール(型名：SPCM-AQ-212)を用いた.Si-APD 受光部の物理的口径は, $0.5 \mathrm{~mm}^{\phi}$ で, 有効口径は $0.45 \mathrm{~mm}^{\phi}$ であ る。波長 $1064 \mathrm{~nm}$ での検出確率は, 測定の結果, $1.0 \% \pm 0.1 \%$

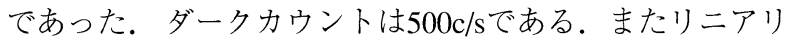
ティは10\%@1Mc/sである. 以上の各構成素子の測定結果 から,レーザー出力, 受信系透過率や受信検出確率などを 合わせた装置パラメー夕総合の測定精度を見積もると, 平 均二乗誤差の和の平方根で考えて $20 \%$ 程度である.

データ取り込みゲート幅を500nsとして, 実験を行った。 このゲート幅は高度分解能 $75 \mathrm{~m} に$ 相当する。

\section{4. 実験結果}

実験場所は宇宙開発事業団筑波宇宙センター内で, 計測 は1997年11月7日17:30〜19:00に行った。この日の天候は 快晴で, 西風が強く地上付近にもエアロゾル等はほとんど 無かった。レーザー光は地上より天空に向かってほぼ鉛 直方向に射出した。実験前後における観測デー夕をFig.3 に示す。デー夕加算回数は, 10,000 回で, $S / N$ は 100 程度であ る. 実験前の計測時刻は17:25JST, 実験後は19:10JSTであ る。この観測データより, 高度 $8 \mathrm{~km}$ 付近で若干変化が見ら れるが, それ以外の高度では, 実験の前後で大気の状態は ほとんど変化していないことが分かる。すなわち, 実験 デー夕は同一条件での観測データと見なすことが出来 る.

Fig.4は, 大気による散乱が空気分子のみによるとしたと きの計算值を実測值に重ねて図示したものである．体積 後方散乱係数 $\beta$ の算出に当たって, 空気分子数密度の高度 分帍は, 米国標隼大気モデル8)在用い, 空気分子によるレー リー散乱の単位分子当たりの断面積は文献9）による值を 用いた。消散係数 $\alpha$ と体積後方散乱係数 $\beta$ との比を表す散 乱パラメー夕Sの值は高度によらず一定で, $S=8 \pi / 3$ を用い た. Fig.4において, 計算值と測定值との差異は, 高度 $5 \mathrm{~km}$ $30 \mathrm{~km}$ で士 20\%程度である。高度 $5 \mathrm{~km}$ 以上では計算值と実 測值は、ほほ一致しているのが分かる。すなわち,この日

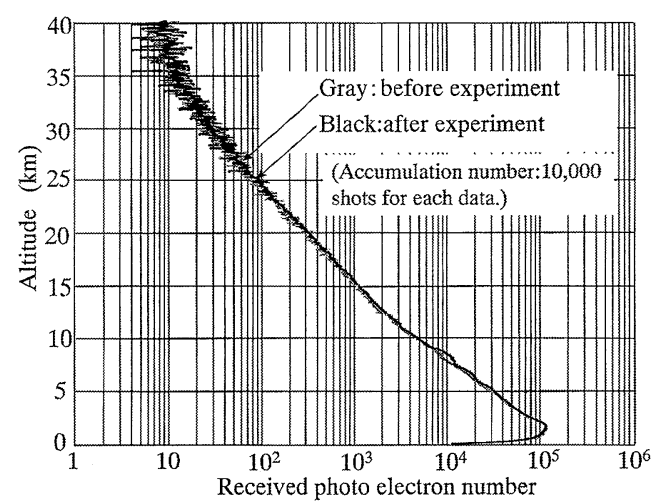

Fig.3 Received photoelectron number before and after experiments. Time is 17:25 JST before experiment and 19:10 after experiment.

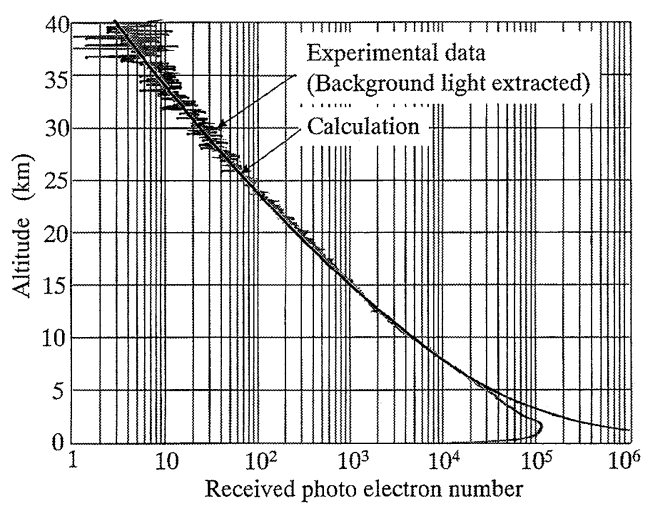

Fig.4 Calculated and experimental received photoelectron number.

の大気はエアロゾルなどが無く, 良く澄んでいたことが分 かる。

$S / N$, 及び受信光電子数分布を算定するため, 加算回数 1 回の計測を100回, 加算回数100回の計測を100回行い実験 データを取得した。

加算回数を変化させたときの受信光電子数と高度との 関係をFig.5に示す. 図中, 加算回数5,10及び20のデータは 1 回加算のデータセットよりランダムに抽出したデータ セットを用いてそれぞれ5,10,200加算処理を行いデー夕

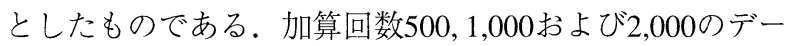
夕は100回加算のデータセットより同上の処理を行ったも のである、1回加算ではS $/ N$ は良く計測出来ないが, 加算回 数が増えるにしたがって, 高高度までS/Nは良く計測出来る ことが分かる.また, 受信光電子数は加算回数に比例して 増加しているのが分かる。

Fig.6に, 受信光電子の確率分布を示す. (a)は加算回数が $\mathrm{K}=1$ 回の場合で, 高度 $5.025 \mathrm{~km}$ のデータである. 図中, 実 線は平均值 $m=2.92$ としたときのPoisson分布の確率分布 式をもちいて計算した結果であり，ほば一致しているのが 分かる. (b) は加算回数を $\mathrm{K}=100$ 回とした場合で, 同じく 高度 $5.025 \mathrm{~km}$ のデータである。この場合には, 平均值 314.8 のPoisson分布になっているのが分かる。 また, 平均值が大 きいため, 分布形状はほぼ正規分布になっている.

計測データより求めた平均值/分散值の值と高度の関係 


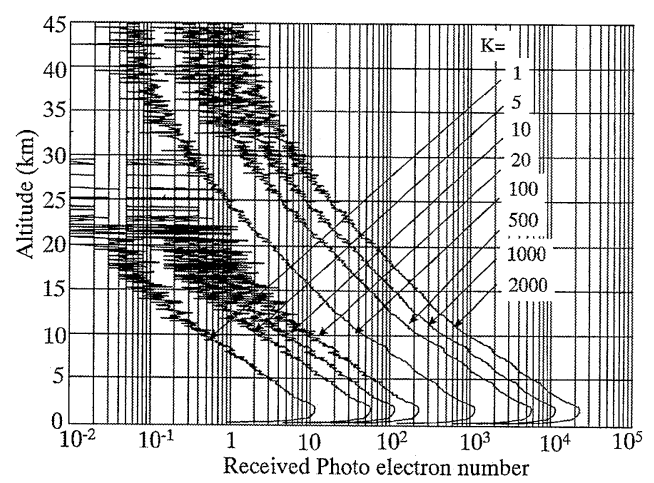

Fig.5 Received photoelectron number as accumulation number changed.

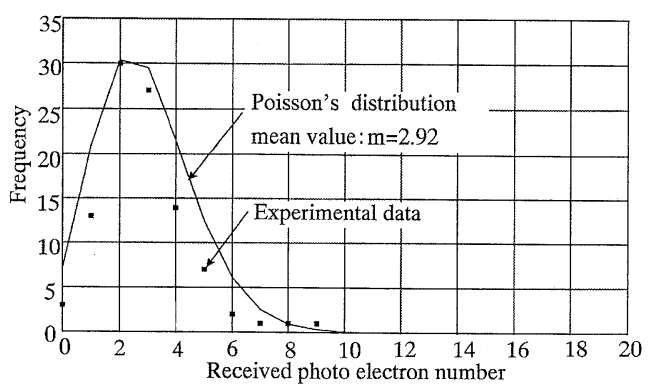

(a)

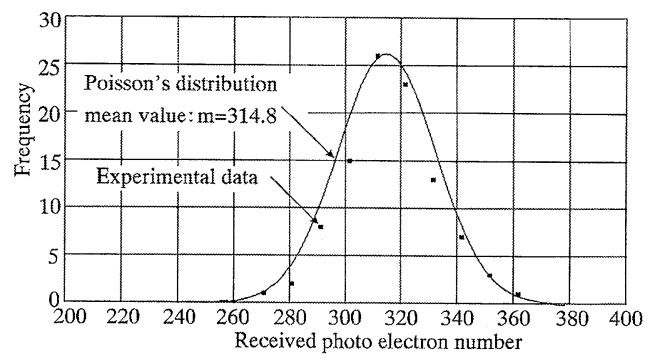

(b)

Fig.6 Received photoelectron distribution (a) In case of the accumulation number of 1 . (b) In case of the accumulation number of 100 . The distribution function is nearly Gaussian, because of the large input photoelectron.

をFig.7に示す．図中, 黒が加算回数 $\mathrm{K}=100$ 回のとき, 灰色 は $\mathrm{K}=1$ のときを示す。高度 $2.5 \mathrm{~km}$ 以上ではいずれも平均 值/分散值の值はほぼ1で，一定であることが分かる。すな わち, 受信光子の分布はPoisson分布であることがわかる. 高度 $2.5 \mathrm{~km}$ 以下では送受光軸にパララックスがあるので, そ の影響が出ている。

Fig.8は, 各高度における加算回数とS/Nの関係を示した ものである．図中, 実線は加算回数 $\mathrm{K}=1$ のときの $S / N$ を基 準とし, $S / N$ は加算回数の平方根に比例するとしたときの計 算值である．計測デー夕を基に最小2乗近似を行った直線 と良く一致する。

\section{5. むすび}

Si-APDフォトンカウンティングモジュールを用いた $1 \mu \mathrm{m}$ 帯のライダー信号の特性について報告した。大気観測

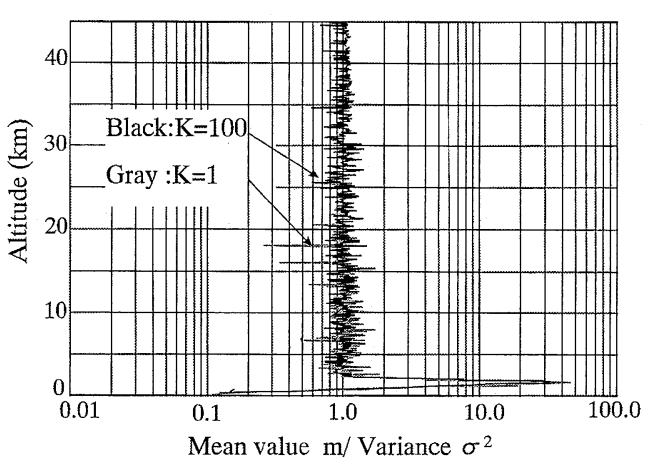

Fig.7 Relation of $m / \sigma^{2}$ vs. altitude. The data below the altitude of $2.5 \mathrm{~km}$ is invalid because of parallax between transmitter optical axis and receiver optical axis.

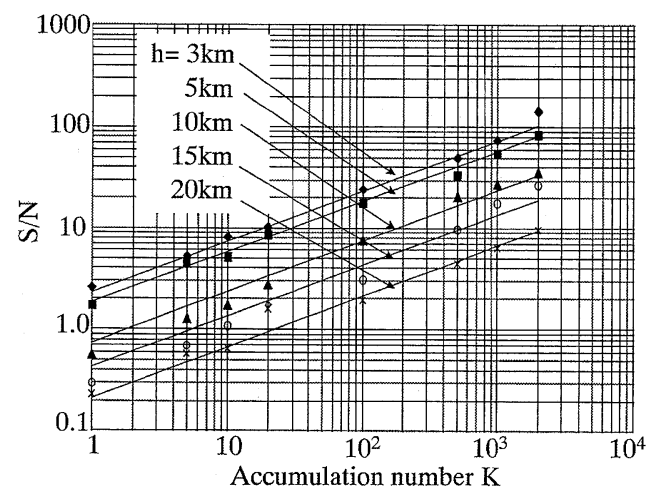

Fig.8 Relation of the accumulation number and signal to noise ratio. $S / N$ increases proportional with square root of accumulation number $\mathrm{K}$.

により得られたライダー信号の受信光電子分布は, Poisson 分布しており, S/Nは加算回数の平方根に比例して増加する ことが分かった。

今後は, $1 \mu \mathrm{m}$ 帯と $0.5 \mu \mathrm{m}$ 帯での計測を同時に行い, ライ ダー信号の分布形状の差異の有無について検討する予定 である。

\section{参考文献}

1) K. Tatsumi, T. Imai, Y. Kawamura, N. Tanioka, T. Aoyagi, and 'T. Takada: Proc. of the 1st work shop on Mission Demonstration Satellite Lidar, 1998 (Earth Science \& Technology Organization,1998) p.16.

2) J. D. Spinhirne and S. P. Palm: Advances in Atmospheric Remote Sensing with Lidar, A. Ansmann, R. Neuber, P. Rairoux, and U. Wandinger(Eds) (Springer-Verlag,1996) p.213.

3) H. Dautet, P. Deschamps, B. Dion, A. D. MacGregor, D. MacSween, R. J. Mcintyre, C. Trottier, and P. P. Webb: Appl. Opt. 32 (1993) 3894.

4) X. Sun and F. M. Davidson: J. of Lightwave Tech. 10 (1992) 1023.

5) J. D. Spinhirne:Trans. on Geoscience and Remote Sensing 31 (1993) 48.

6) R. M. Measures: Laser Remote Sensing, Fundamentals and Applications. (KRIEGER PUBLISHING COMPANY, MALABAR, FLORIDA, 1992) p.237.

7) 花村 栄一：量子光学 (岩波講座 現代の物理学 8 , 岩波書店, 1992) p.72.

8) U. S. Standard Atmosphere, 1976 (U. S. Government Printing Office, Washington, D. C., 1976)

9) A. Bucholtz: Appl. Opt. 34 (1995) 2765. 